\title{
Strength Characteristics of M40 Grade Concrete using Waste PET as Replacement for Sand
}

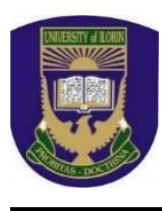

\author{
S. O. A. Olawale, M. A. Kareem*, O. Y. Ojo, A. U. Adebanjo, M. O. Thanni \\ Department of Civil Engineering, Osun State University, Osogbo, Nigeria.
}

ABSTRACT: The wide variety of industrial and domestic applications of plastic products has fuelled a global trend in their use. The vast amount of plastic items that are discarded after use, on the other hand, pollutes the environment. In light of this, the current study investigated the use of Polyethylene Terephthalate (PET) as substitute for natural sand in concrete production. Locally sourced river sand was replaced with industrially ground waste PET in proportions of 4 to $20 \%$ at a step of $4 \%$ by the weight of natural sand whereas other concrete constituents (cement, granite, watercement ratio and superplasticizer) were kept constant. A Grade M40 concrete with a mix proportion of 1:1:2:0.35 (cement: sand: granite: water-to-cement ratio) was used for all concrete mixes. Concrete without PET represents the control. Fresh (Slump) and hardened (compressive, split tensile and flexural) properties of the produced concrete were assessed using standard testing methods. The results showed that the slump of concrete decreased by $1.8 \%$ and $12.5 \%$ with an increase in PET content from 0 to 20\%. The 28-day compressive strength of concrete containing PET was lower than the control. However, concrete with 4\% PET compared considerably well with control with the compressive strength value exceeding the target strength of $40 \mathrm{~N} / \mathrm{mm}^{2}$ while concretes containing PET beyond $4 \%$ had compressive strength below the target strength. The split tensile strength of concrete containing $4 \%$ PET was higher than that of the control but exhibited lower flexural strength than the control at the age of 28 days. It was concluded that the reuse of PET as a substitute for natural sand as an alternative waste disposal solution for ecofriendly concrete development and attainment of a pollution-free environment is viable.

KEYWORDS: Compressive strength, concrete, polyethylene terephthalate, target mean strength, workability.

\section{INTRODUCTION}

Concrete is a composite material that is composed of binder, aggregates (fine and coarse), and water. It is commonly used for structural applications such as buildings, roads, bridges, tunnels, dams, pipes, and sewerage systems construction. Aggregates account for about $65 \%$ to $80 \%$ of the total concrete volume (Saikia and de Brito, 2014). Thus, aggregates play an essential role in the overall concrete performance and cannot be overlooked. The high demand for aggregate in concrete production is due to its roles in improving strength, thermal, elastic properties and dimensional stability for concrete (Saikia and de Brito, 2014; Kaushal and Vasistha, 2018; Nadimalla et al., 2019). Man's reliance on the natural aggregate as the only aggregate source in construction industries is not sustainable coupled with the fact that the mining of the aggregate is a major source of environmental degradation. For example, uncontrolled mining of river sand leads to degradation such as; erosion, compromised riverbanks, reduction of riverbeds, looming damage of structures built near the rivers and flooding among others (Hemalatha and Prakash, 2017; Gopi et al., 2020; Ajamu et al., 2020). The need to conserve natural resources and minimize environmental degradation has led to the search for substitutes that are readily available, cheap and environmentally friendly than conventional aggregates.

Several materials which have been used as a replacement for fine aggregate (FA) in concrete production are recycled glass, iron filling, rice husk, ceramic, waste PET bottle, crumb rubber. Results from a report on the use of recycled glass waste indicate that at 28-day the strength of concrete containing waste glass was 1.3 times higher than that of ordinary concrete (Adaway and Wang, 2015). Samantaray et al. (2016) discovered that $30 \%$ of rice husk ash and iron filling as partial replacements for sand, produced concrete with optimum compressive strength. For instance, the use of bone china ceramic as FA was found to improve the concrete's resistance to acid attack (Siddique et al., 2019). Similarly, Mastan and Asadi (2017) found that the concrete strength properties were greatly influenced by the addition of Polyethylene Terephthalate (PET) waste as FA. Issa and Salem (2013) utilized $25 \%$ of crumb rubber waste (CRW) as 
FA in concrete mix and reported an acceptable compressive strength than the control samples.

PET is a thermoplastic polymer that belongs to the polyester family of polymers. It is used in the manufacture of plastic bottles, food containers and cloth fibres (Frigione, 2010; Lee et al., 2019). Plastic materials are among the largest materials that contribute to solid waste pollution since they are commonly discarded after every use (Lee et al., 2019). According to Chhazed et al. (2019), the global production of plastic products increased from 2 to 380 million tonnes with a cumulative of 7.8 trillion tonnes from 1950 to 2015. Nigeria was ranked the second country in Africa after Egypt with the largest amount of plastic imports and consumption estimated as 19.9 million tonnes between 1990 and 2017 (Babayemi et al., 2019). The disposal of these huge quantities of waste PET into the environment constitutes hazards to man and negatively affect the environment because they are nonbiodegradable (Chhazed et al., 2019; Almeshal et al., 2020).

Plastic products are used extensively in healthcare delivery systems by patients, health and social personnel in order to implement preventive measures. The widespread use of protective gear around the world, according to Kleme et al. (2020), has led to major supply chain disturbances and downstream waste management issues. Plastic materials used as PPE by health staff, such as masks, gloves, and syringes, are discarded after each use. Incineration as a waste disposal technique has a higher environmental impact because the energy in plastic products is lost, resulting in a large release of greenhouse gases and toxic compounds into the atmosphere (Heidari et al., 2019; Lee et al., 2019). These waste management activities has placed human society and the rest of the world in jeopardy. Other negative consequences of waste PET mismanagement include disease transmission because discarded PET can serve as a breeding ground for mosquitoes, flooding due to waste PET blocking river channels and drains. Loss of aesthetics of the environment where waste PET litters the environment, and scarcity of land for productive uses in an area where good deal of land space is used for landfill or as dumpsite are other possible challenges due to waste PET mismanagement (Abdulkarim and Abiodun, 2012).

The reuse of waste arising from poor disposal of PETbased products in concrete production can be an effective measure to conserve natural aggregate resources and reduce environmental burdens resulting from waste PET disposal (Mastan and Asadi, 2017). According to Lee et al. (2019), waste PET are cheap and readily available materials due to its use for domestic packaging of daily human needs, some of its engineering properties such as density, malleability and ductility make it a choice material in concrete technology.

In recent years, several studies have assessed and identified different optimum levels of PET as a partial replacement for conventional fine aggregates in concrete. Ajagbe et al. (2018) produced M20 grade concrete by using shredded waste plastic as a substitute for sand. In similar efforts, Mastan and Asadi (2017) used waste PET as FA in concrete of grades M20, M25 and M30 at percentage replacement of 5 to $25 \%$ at an increment of 5, respectively, was investigated to understand the effect of varying cement content. Gopi et al., (2020) also used various forms of waste plastic as a partial substitute for sand to develop M30 grade concrete while Almeshal et al. (2020) evaluated the use of the same material in producing concrete with a design strength of $35 \mathrm{MPa}$ at 28 days for normal strength concrete.

According to the literature (Mastan and Asadi, 2017; Ajagbe et al., 2018; Almeshal et al., 2020; Gopi et al., 2020), PET has been considered as partial substitute for sand in the production of concrete with a design strength of up to $35 \mathrm{MPa}$, but PET as a replacement for sand in concrete with a design strength of $40 \mathrm{MPa}$ is not widely known. As a result, this study examines the strength characteristics of M40 grade concrete made with different percentages of ground waste PET as a sand replacement, in order to determine the optimum amount of PET as a sand replacement for sustainable concrete production and to develop an alternative method of utilizing wastes emanating from the disposal PET wastes.

\section{A. Materials}

\section{MATERIALS AND METHODS}

The materials used are Dangote Portland limestone cement grade 32.5R CEM II/B-L, river sand, granite, water, waste PET and Conplast SP 430 superplasticizer. The cement with a specific gravity of 3.06 which conforms to BS EN 197 1 (2011) was used as the binder. River sand and industrially crushed waste PET (Figure 1) were used as FA, the coarse aggregate used was crushed granite. Conplast SP 430 superplasticizer with a manufacturer specified specific gravity of 1.19 was used as the chemical admixture.

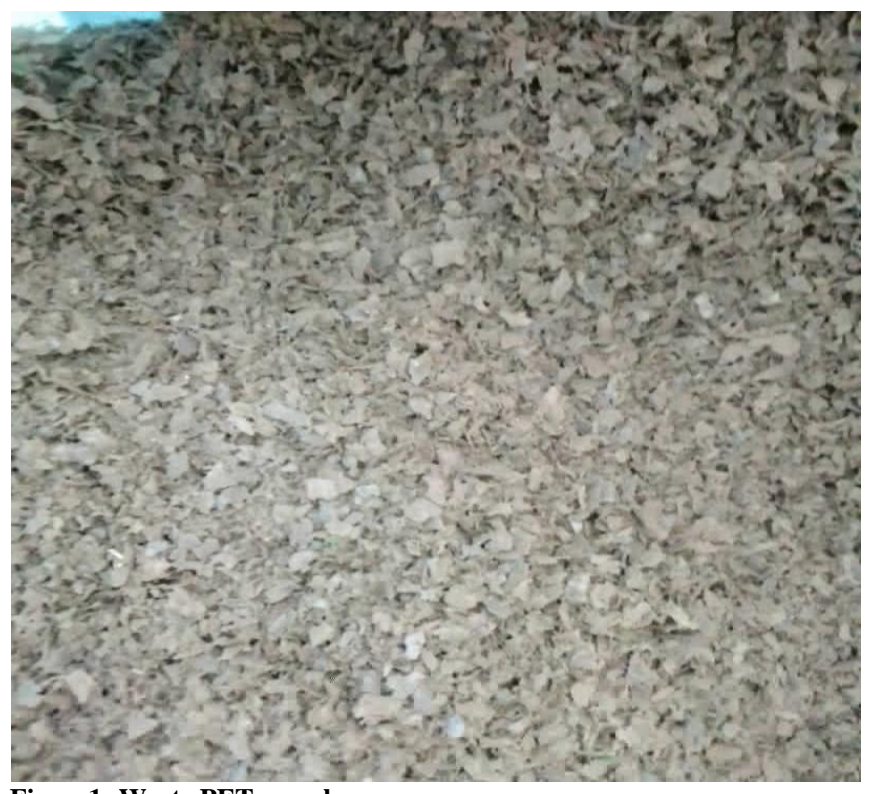

Figure1: Waste PET sample.

\section{B. Experimental Methods}

\section{1.) Materials characterization}

Sieve analysis was conducted on aggregates (river sand, granite and waste PET) to determine particle size distribution as specified in ASTM D2487 (2000). The physical properties of aggregates such as specific gravity, fineness modulus and particle size were determined as specified in ASTM C127 
(2012) and ASTM C136 (2006). The concrete constituents were mixed using water from a clean source.

\section{2.) Mix design and specimens preparation}

The mix proportion of 1:1:2 (cement: sand: granite) designed for M40 Grade concrete with a w/c ratio of 0.35 was adopted. Five concrete mixes were prepared by replacing conventional FA with 4, 8, 12, 16 and $20 \%$ ground waste PET by weight. The concrete without waste PET represents the control. The cement, granite, w/c ratio and superplasticizer contents were unchanged for all the concrete mixes. Table 1 shows the details of the mix proportion for producing $1 \mathrm{~m}^{3}$ of concrete. The mixing of concrete was done manually as specified in BS1881-125 (2013).

Thereafter, concrete mixes were cast in metallic moulds and the mould with the concrete specimens were placed in the curing room at $27 \pm 5{ }^{\circ} \mathrm{C}$. The concrete specimens were unmoulded and later cured in water until the testing ages were reached. Two hundred and sixteen (216) concrete specimens were produced in the laboratory, consisting of; seventy-two (72), $150 \mathrm{~mm}$ cubes; seventy-two (72), $150 \mathrm{~mm}$ diameter and $300 \mathrm{~mm}$ height cylindrical concrete and seventy-two (72), 150 $\mathrm{mm}$ width, $150 \mathrm{~mm}$ depth and $500 \mathrm{~mm}$ length prisms, respectively for compressive, split tensile and flexural strength tests, respectively.

\section{3.) Properties of fresh and hardened concrete}

Slump test was conducted on fresh concrete in compliance with BS EN 12350-2 (2019). The bulk density was determined for hardened concrete at 28 days curing age as specified in BS EN 12390-7 (2019). Compressive, splitting tensile and flexural strengths tests were conducted on hardened concrete specimens at the age of 7, 14, 21 and 28 days using the Universal Testing Machine with a capacity of $2000 \mathrm{kN}$ according to BS EN 12390-3 (2019), BS EN 123906 (2019) and BS EN 12390-5 (2019), respectively at the defined testing ages. The flow chart showing the experimental process is illustrated in Figure 2.

\section{RESULTS AND DISCUSSION}

\section{A. Result of Physical Properties}

The physical properties of aggregates are shown in Table

2. Based on the particle size distribution of aggregates
(Figure 3 ), the coefficient of uniformity $\left(\mathrm{C}_{\mathrm{u}}\right)$ values for sand, granite and waste PET are 3.61, 2.21 and 1.07 while the coefficient of curvature $\left(\mathrm{C}_{\mathrm{c}}\right)$ are $0.45,0.92$ and 1.01, respectively. The $C_{u}$ value for sand is approximately 4 and $C_{c}$ value is less than 1 as specified by unified soil classification system (USCS) as postulated in ASTM D2487 (2011). The $\mathrm{C}_{\mathrm{c}}$ values for granite and waste PET are closed to 1, indicating that both are well graded while the $\mathrm{C}_{\mathrm{u}}$ values of less than or equal to 4 for both suggest that both are uniformly graded (Iowa, 2020). These findings suggest that the aggregates used are suitable for concrete production. The specific gravity values for sand, granite and waste PET are 2.65, 2.71 and 1.07, respectively. The specific gravity values of sand fall within the range of 2.6-2.8 specified for normal weight aggregates according to ACI Education Bulletin EI (1999) while the waste PET having the specific gravity value below this range can be categorised as lightweight aggregate.

\section{B. Workability of Concrete}

The influence of waste PET on the concrete slump are presented on Table 3. The measured slump values of concrete decreased with the addition of waste PET in concrete. The reduction in slump values were $2 \%, 4 \%, 7 \%, 10 \%$ and $12.5 \%$ for concrete with 4, 8, 12, 16 and $20 \%$ waste PET content relative to control. Consequently, the reduction in workability of high-grade PET concrete suggests that higher water content will be required by the concrete containing waste PET to achieve more practicable workability that is comparable to that of concrete without PET. This is corroborated with the findings of Akinyele and Ajede (2018), Mustafa et al., (2019) and Almeshal et al., (2020). The decrease in workability of concrete with an increasing PET content was attributed to the fact that the plastic in the mix was not able to absorb the excess water thereby making a dry slump (Umasabor and Daniel, 2020). Thus, to achieve a similar degree of workability as experienced by the control, a higher water-tocement ratio will be required by the PET concrete.

Table 1: Quantity of materials used for producing $1 \mathrm{~m}^{3}$ of concrete.

\begin{tabular}{|c|c|c|c|c|c|c|}
\hline \multirow{2}{*}{ Materials } & \multicolumn{6}{|c|}{ Waste PET Content (\%) } \\
\hline & 0 (Control) & 4 & 8 & 12 & 16 & 20 \\
\hline Cement $(\mathrm{kg})$ & 366 & 366 & 366 & 366 & 366 & 366 \\
\hline Sand $(\mathrm{kg})$ & 366 & 351 & 337 & 322 & 307 & 293 \\
\hline Granite $(\mathrm{kg})$ & 732 & 732 & 732 & 732 & 732 & 732 \\
\hline Waste PET (kg) & 0.00 & 15 & 30 & 45 & 60 & 75 \\
\hline Water (kg) & 110 & 110 & 110 & 110 & 110 & 110 \\
\hline Admixture (\%) & 0.37 & 0.37 & 0.37 & 0.37 & 0.37 & 0.37 \\
\hline
\end{tabular}




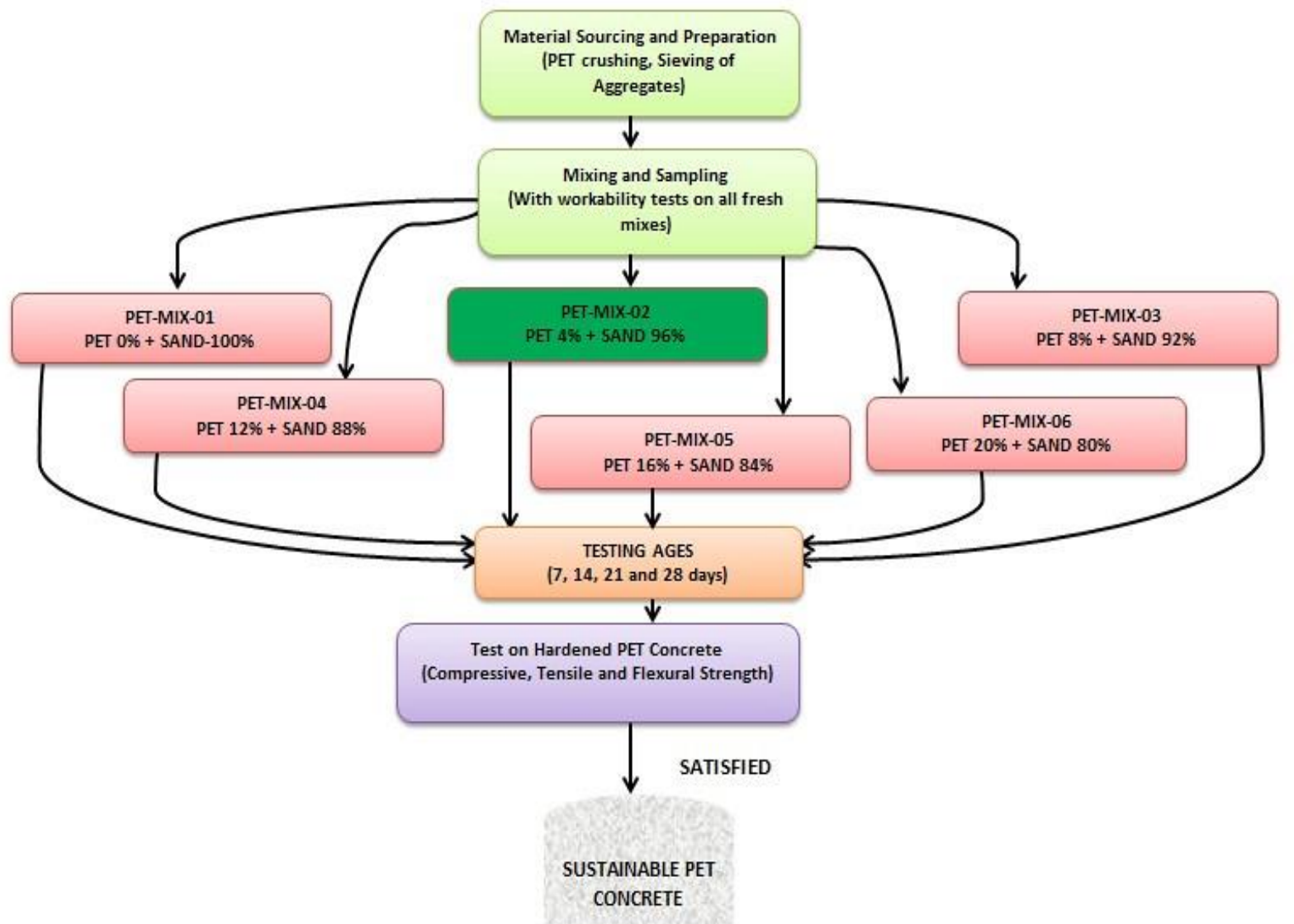

Figure 2: Flowchart of the experimental setup.

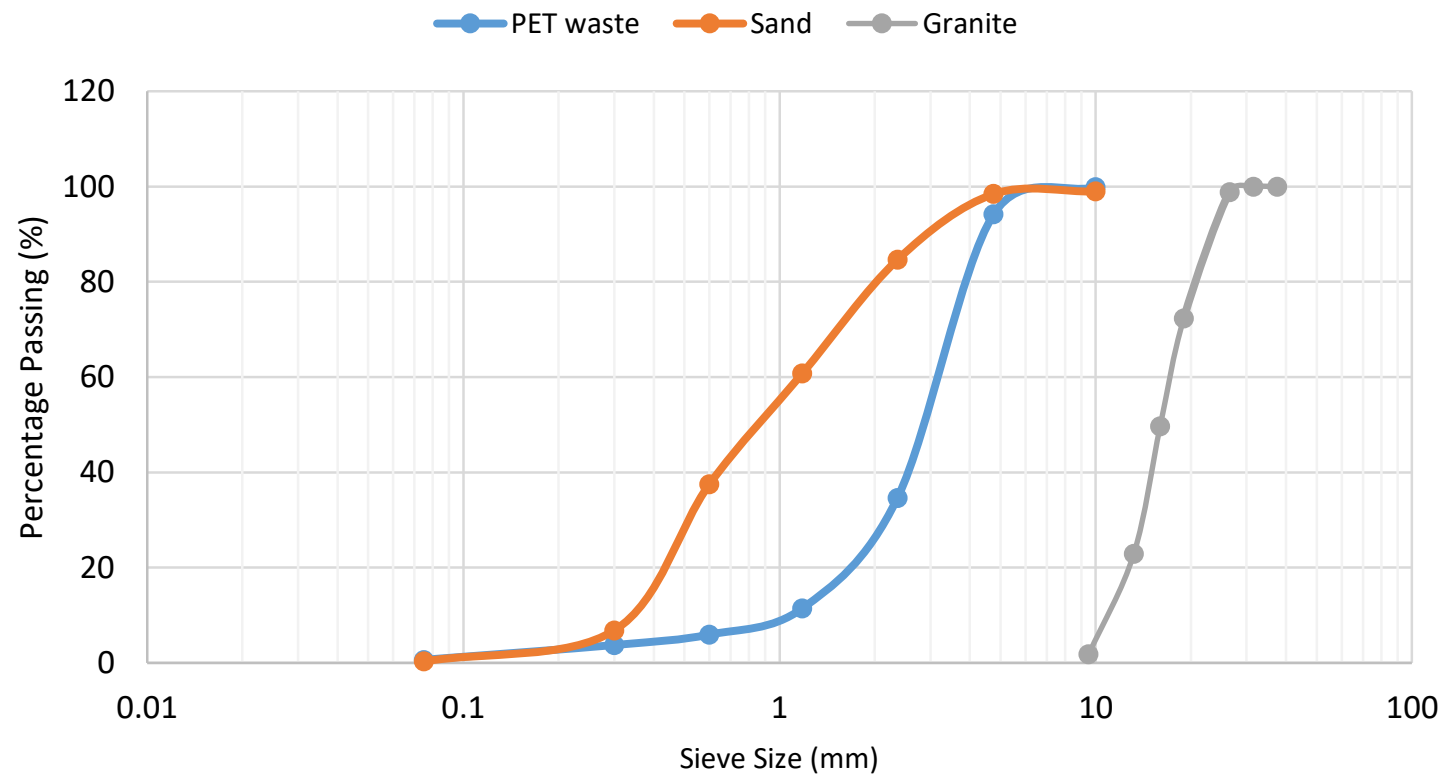

Figure 3: Gradation curves of the aggregates. 
Table 2: Physical properties of constituent materials.

\begin{tabular}{lcccc}
\hline Properties & Sand & Granite & Waste PET & $\begin{array}{c}\text { Normal weight } \\
\text { Aggregate* }\end{array}$ \\
\hline Coefficient of uniformity & 3.61 & 2.21 & 1.07 & - \\
Coefficient of curvature & 0.45 & 0.92 & 1.01 & - \\
Fineness Modulus & 4.12 & 3.54 & 5.50 & $2.3-3.0$ \\
Specific Gravity & 2.65 & 2.71 & 1.07 & $2.6-2.8$ \\
Particle Size (mm) & $<2.36$ & $<19.00$ & $<2.36$ & - \\
\hline
\end{tabular}

* ACI Education Bulletin EI (1999)

Table 2: Slump values of fresh concrete with waste PET.

\begin{tabular}{ccc}
\hline Waste PET Content (\%) & Slump (mm) & Degree of workability \\
\hline 0 & 28 & Low \\
4 & 27.5 & Low \\
8 & 27 & Low \\
12 & 26 & Low \\
16 & 25 & Low low \\
20 & 24.5 & Very low \\
\hline
\end{tabular}

\section{Density of PET Concrete}

The density of concrete produced with different waste PET contents at 28 days of curing are presented in Figure 4. The results showed that the density of concrete ranged from 2204 to $2595 \mathrm{~kg} / \mathrm{m}^{3}$ as PET content increases from 0 to $20 \%$. This range of concrete density is in line with the range of 2200 to $2600 \mathrm{~kg} / \mathrm{m}^{3}$ as stated in (Neville, 2011) for normal-weight concrete. It was found that the density of concrete decreased by $3 \%, 4 \%, 7 \%, 10 \%$ and $11 \%$ as the waste PET content increased from 0 to $20 \%$, respectively relative to control. These results indicate that concretes containing waste PET are less dense than the normal aggregate concrete, this could be as a result of the low specific gravity of the PET aggregates.

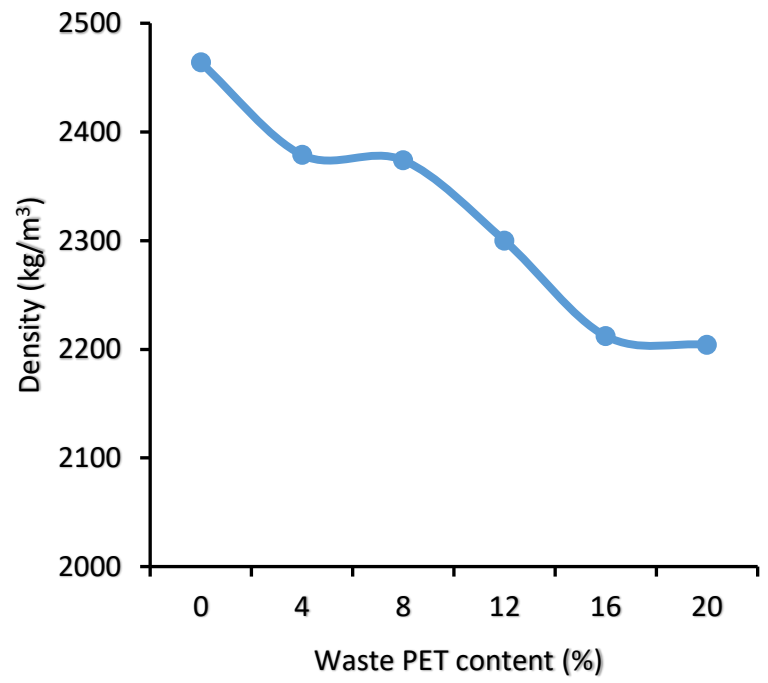

Figure 4: Density of concrete with waste PET.
This is in agreement with the previous observation of (Mohammed et al., 2019). The decrease in density of concrete with waste PET can be attributed to the replacement of denser material (sand) with lighter material (waste PET) (Saikia and de Brito, 2014; Almeshal et al., 2020).

\section{Compressive Strength of Concrete}

The compressive strength of concrete with various waste PET content at the curing ages of 7,14 , and 28 days are as shown in Figure 5. In general, the compressive strength of concrete increases as the curing ages progress from 7 to 28 days. However, with an increase in the addition of waste PET, a decline in compressive strength was observed relative to control. The compressive strength obtained for control increased from 39.6 to $43.4 \mathrm{~N} / \mathrm{mm}^{2}$ as the curing age advances from 7 to 28 days, which represents about $9 \%$ increment in strength. This indicates that by the 28th day, the control had exceeded the target strength for grade 40 M40 concrete as stated in BS EN 1992-1-1:2004+A1 (2014). An increase in compressive strength values of $10 \%, 18 \%, 24 \%, 27 \%$ and $20 \%$ was recorded for concrete containing $4 \%, 8 \%, 12 \%, 16 \%$ and $20 \%$ waste PET contents as the curing age rose from 7 to 28 days. This shows the increasing trend of compressive strength with curing age.

At 28 days of curing, the compressive strength values of $42.6 \mathrm{~N} / \mathrm{mm}^{2}, 38.9 \mathrm{~N} / \mathrm{mm}^{2}, 38.6 \mathrm{~N} / \mathrm{mm}^{2}$ and $36.8 \mathrm{~N} / \mathrm{mm}^{2}$ were obtained for concrete with 4 to $20 \%$ waste PET. All the concrete containing waste PET achieved the strength below the target strength for grade M40 with the exception of concrete with $4 \%$ waste PET content which had the strength value above the target strength for M40 concrete specified by BS EN 1992-1-1:2004+A1 (2014). This result indicates that concrete with $4 \%$ waste PET content gave a satisfactory strength requirement. 


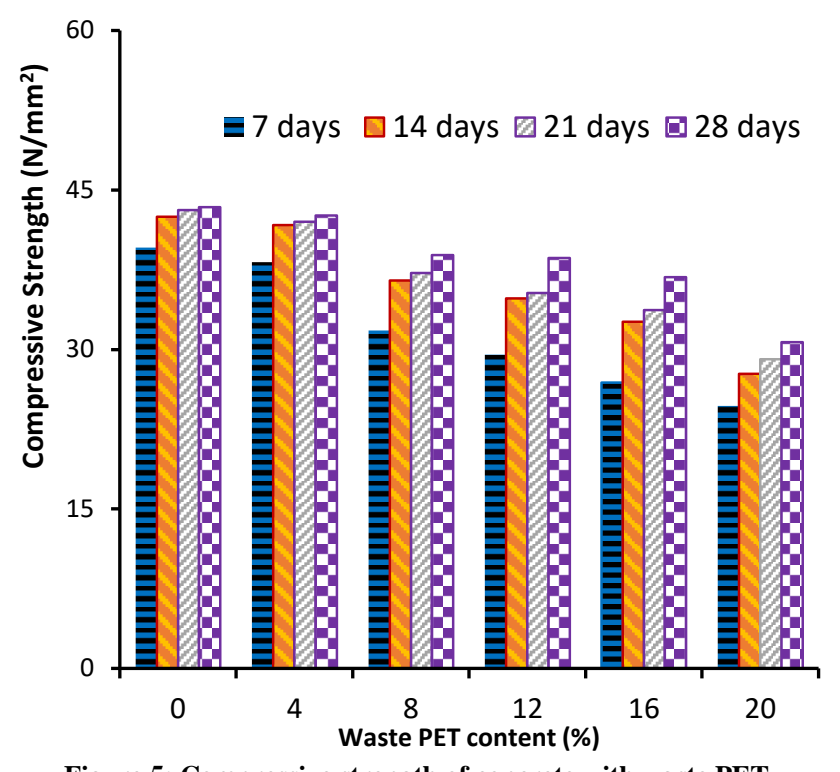

Figure 5: Compressive strength of concrete with waste PET.

The reduction in compressive strength of $2 \%, 10 \%, 11 \%$, $15 \%$ and $29 \%$ were observed with rise in the content of waste PET in concrete from 4 to $20 \%$ relative to control at 28 days. This indicates that the concrete produced with waste PET had lower values of compressive strength as compared with the control. The drop in the strength of concrete with waste PET may be the consequence of the low specific gravity of waste PET aggregates. The lack of adhesion between the surfaces of waste PET and cement matrix can also hinder the strength of concrete (Almeshal et al., 2020). The finding agrees with the observations from previous studies (Akinyele and Ajede, 2018; Almeshal et al., 2020).

The connection between concrete 28-compressive strength and density of waste is shown in Figure 6. Concrete density and 28-day compressive strength were decreased as the addition of waste PET increased, and a linear equation with a determination coefficient $\left(\mathrm{R}^{2}\right)$ value of 0.7521 was found.

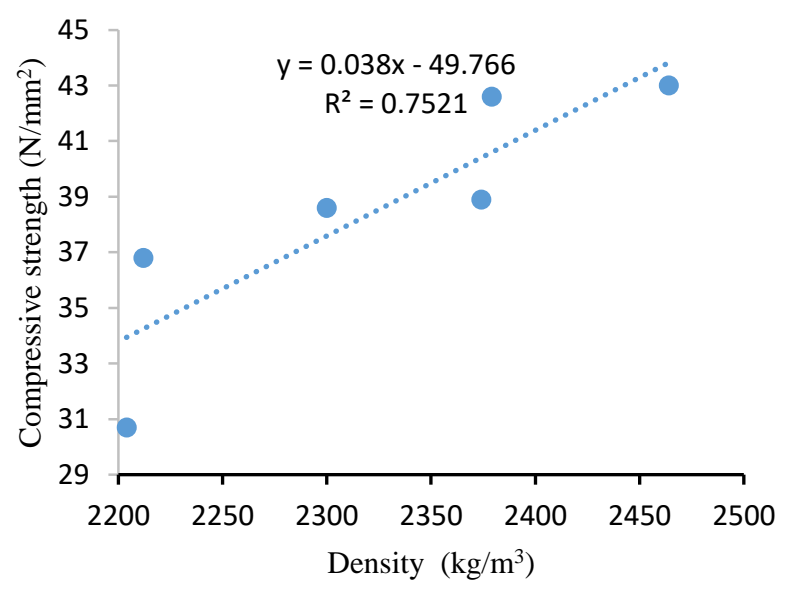

Figure 6: Relation between compressive strength and density with waste PET.
The linear equation relating the compressive strength and density of concrete with waste PET is given in the expression in Eq. 1.

$f_{c c}=0.038 d_{c}-49.766 \quad R^{2}=0.7521$

where,

$f_{c c}=$ cube compressive strength of concrete and

\section{E. Split Tensile Strength of Concrete}

The split tensile behaviour of concrete with waste PET across the ages of curing (7, 14, 21, and 28 days) are shown in Figure 6. The split tensile strength exhibited a similar trend as observed for the compressive strength. This result shows that the incorporation of waste PET into concrete compromised the concrete's splitting tensile strength and compared with reference concrete. However, only the concrete with $4 \%$ of waste PET gave a fairly significant outcome. However, with all the concrete samples tested, the split tensile strength of concrete increased as the curing age increases.

The tensile strength of the control under consideration increased from 4.09 to $4.36 \mathrm{~N} / \mathrm{mm}^{2}$ as the days of curing increased from 7 to 28 , this shows an increment of $6 \%$ in tensile strength and represents about two-third of the increment recorded for compressive strength. An increase in tensile strength values of $5 \%, 17 \%, 22 \%, 25 \%$ and $22 \%$ were also recorded for concrete containing $4,8,12,16$ and $20 \%$ as the days of curing increased from 7 to 28 . The tensile strength of concrete increase as the curing age increases, which is the similar trend observed for compressive strength.

At 28 days of curing, concrete containing $4 \%$ waste PET achieved the split tensile strength value of $4.4 \mathrm{~N} / \mathrm{mm}^{2}$, representing an increase of $1.6 \%$ compared with the control, whereas the reduction of $6 \%, 7 \%, 10 \%$ and $19 \%$ were obtained for concrete containing 8, 12, 16 and 20\% waste PET content with respect to control. The initial increase of tensile strength may be attributed to the PET having proper bonding with the fine aggregate, while the decrease of tensile strength beyond $4 \%$ may be due to the decrease in adhesive strength between the surface of the waste plastic and the cement paste (Umasabor and Daniel, 2020). As reported by Almeshal et al. (2020), the low tensile strength observed for PET concrete may be due to the variation in shape and poor stiffness of the waste PET aggregate. This finding agrees with the observations from previous studies (Akinyele and Ajede, 2018). This result indicates that concrete with $4 \%$ waste PET content exhibit the potentials to increase the concrete cracking resistance due to tension failure.

The relationship between the 28-day split tensile and compressive strengths of concrete with waste PET are shown in Figure 7. As the inclusion of waste PET in the conventional concrete increased, the compressive and split tensile strengths of concrete decreased, suggesting a very close relationship between the two properties with a coefficient of determination $\left(\mathrm{R}^{2}\right)$ value of 0.9898 . The power equation relating the split 
tensile and compressive strengths of concrete with waste PET is expressed using Eq. 2.

$$
f_{c t}=0.3435 f_{c c}^{0.677} \quad R^{2}=0.9864
$$

where

$$
\begin{gathered}
f_{c t}=\text { split tensile strength of concrete and } \\
f_{c c}=\text { cube compressive strength of concrete }
\end{gathered}
$$

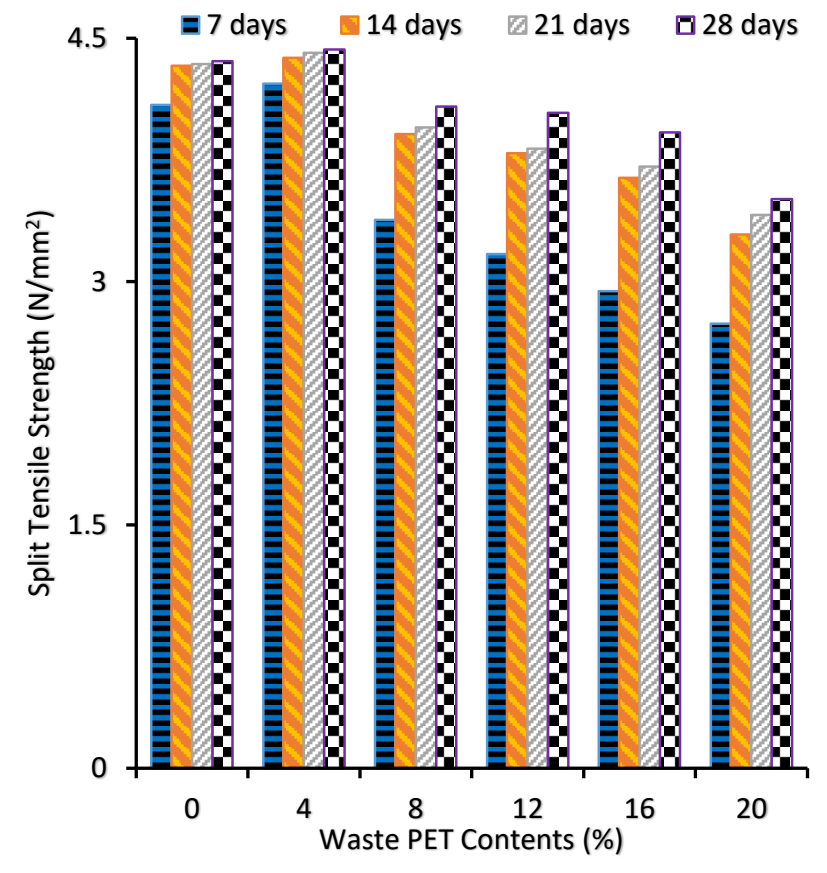

Figure 6: Split tensile strength of concrete with waste PET.

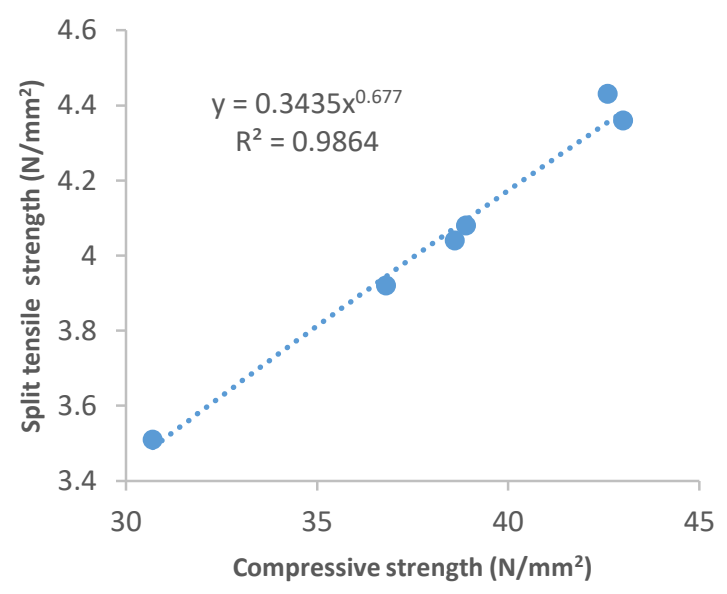

Figure 7: Relation between split tensile and compressive strengths of concrete with waste PET.

\section{F. Flexural Strength of Concrete}

The behaviour of the concrete in bending (flexure) across the ages of curing $(7,14,21$, and 28 days) are shown in Figure 8. Unlike the results obtained for tensile strength, as the proportion of waste PET increased, there was an overall decrease in the flexural strength of PET concrete, however, curing of the concrete improved its flexural strength across the period of testing. The flexural strength of the control increased from 6.45 to $7.89 \mathrm{~N} / \mathrm{mm}^{2}$ which represents an increase of $18 \%$ as the curing age increased from 7 to 28 days. For samples with waste PET the percentage increment in flexural strength values for the same period of curing are $23 \%, 30 \%, 32 \%, 36 \%$ and $55 \%$ for $4,8,12,16$ and $20 \%$ replacement values respectively. The flexural strength followed the same trend as compressive and split tensile strengths with increase in tensile strength values as the curing age increased.

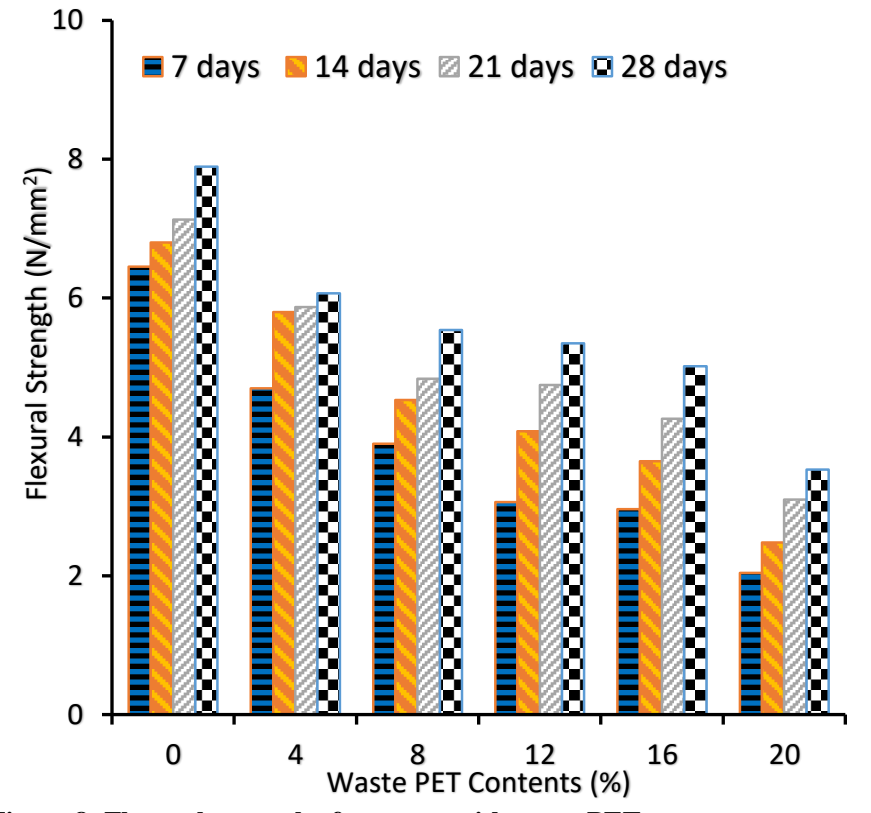

Figure 8: Flexural strength of concrete with waste PET.

Compared with the control, the 28-day flexural strength of concrete containing $4,8,12,16$ and $20 \%$ waste PET decreased by $23 \%, 30 \%, 32 \%, 36 \%$ and $55 \%$. This indicates that the concrete produced with waste PET had lower values of flexural strength as compared with the control. The decrease of tensile strength may be due to the decrease in adhesive strength between the surface of the waste PET and the cement paste (Umasabor and Daniel, 2020). According to Almeshal et al. (2020), the low flexural strength observed for PET concrete may be related to the low strength of waste PET and the low bonding strength between the cement matrix and waste PET at the interfacial transition zone. This finding corroborates with the observations from previous studies (Safi et al., 2013; Jaivignesh and Sofi, 2017). It can be seen from Figure 9 that concrete with 4\% waste PET content exhibited the lowest reduction in flexural strength value compared with those with higher waste PET contents. This suggests that waste PET possess the ability to reduce the brittleness of concrete which is similar to the control at an optimum level of replacement of waste PET.

The relationship between the 28-day flexural strength and compressive strength of waste PET concrete is shown in Figure 9. As the content of waste PET in concrete rises, the 28-day compressive strength and flexural strengths were continuously decreased. A coefficient of determination $\left(\mathrm{R}^{2}\right)$ 


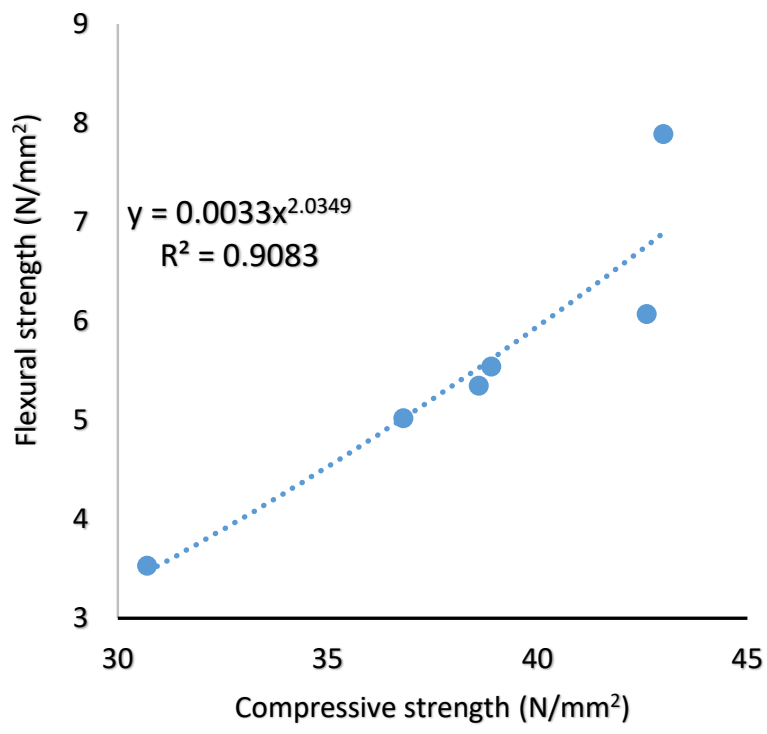

Figure 9: Relation between flexural and compressive strengths of concrete with waste PET.

value of 0.9083 indicated that the 28-day compressive strength of waste PET concrete is strongly related to its flexural strength. The power equation relating the flexural and compressive strengths of concrete with waste PET is given in Eq. (3).

$f_{c t}=0.0033 f_{c c}^{2.0349} \quad R^{2}=0.9083$ where,

$f_{c f}=$ flexural strength of concrete

$f_{c c}=$ cube compressive strength of concrete

G. Model For Predicting The Strength Properties of Waste PET Concrete

Statistical models were developed using multiple linear regression analysis to predict the compressive, splitting tensile and flexural strengths of Grade M40 concrete with waste PET and curing ages. The regression models are presented as Eqs. (4) to (6), respectively. In the model, linear parameters were significant with $p$-values $<0.05$. This suggests that there exists a significant relationship between the independent and dependent variables. The magnitude of error observed between the actual experimental values and the predicted values for all the samples tested are shown in Figure 10. It can be seen from this figure that the range of error is between $\pm 2.7 \mathrm{~N} / \mathrm{mm}^{2}$, with compressive strength being the highest and flexural strength of concrete being the lowest.

$f_{c c}=37.511-69.95 p c+0.30 c d$

$f_{c t}=3.89-5.54 p c+0.029 c d$

$f_{c f}=5.25-19.08 p c+0.078 c d$

where,

$f_{c c}=$ compressive strength of concrete

1) $f_{c t}=$ split tensile strength of concrete

$f_{c f}=$ flexural strength of concrete

$p c=$ waste PET content

$c d=$ curing days

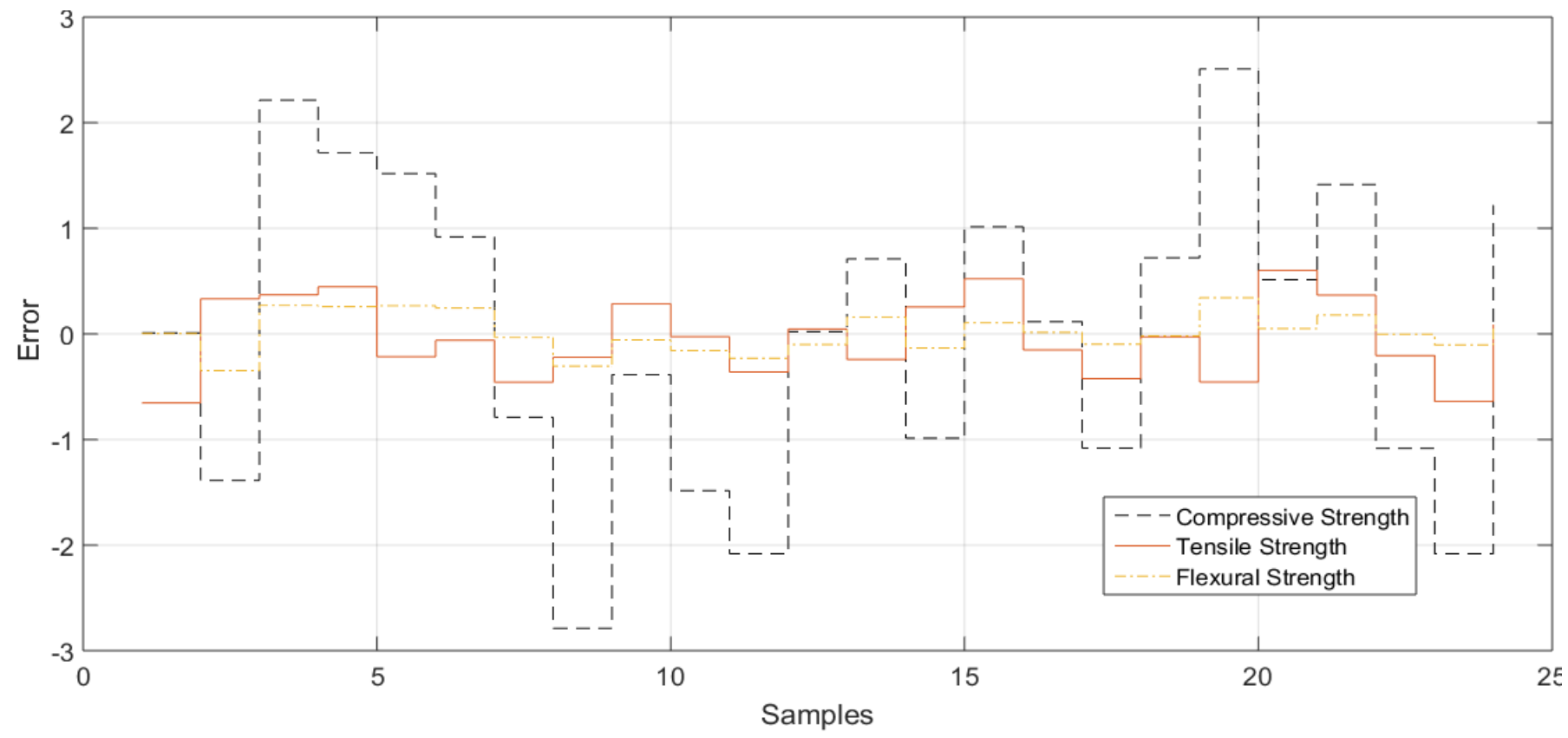

Figure 13: Magnitude of error between the predicted and actual experimental values. 


\section{CONCLUSION}

The following conclusions could be drawn from the findings of this work.

1) As the waste PET content increased, the workability of concrete with partially substituted waste PET aggregates declined.

2) The hardened density of waste PET concrete is lower compared with reference concrete and the trend is increasing with increasing waste PET aggregates contents.

3) The compressive strength values of concretes with waste PET were lower than that of the reference concrete, and the trend increased as waste PET content in concrete increased. The 28-day compressive strength of the reference concrete and concrete with $4 \%$ waste PET content were higher than the strength value of $40 \mathrm{~N} / \mathrm{mm}^{2}$ for M40 grade considered in the design while those with higher PET contents did not meet this criterion.

4) The split tensile strength values of concrete with waste PET were lower compared with reference concrete, except for concrete with $4 \%$ waste PET having a slightly higher split tensile strength value than the reference concrete.

5) Concrete with waste PET had lower flexural strength values at all curing ages. However, when compared with other concrete with waste PET, concrete with $4 \%$ of waste PET exhibited a very satisfactory result.

6) For the achievement of the M40 grade concrete requirement, an optimum percentage of $4 \%$ waste PET substitution for sand is considered most acceptable.

\section{REFERENCES}

ACI Education Bulletin E1 (1999). American Concrete Institute, Aggregates for concrete, Developed by Committee E-701, Materials for Concrete Construction.

Adaway, M. and Wang, Y. (2015). Recycled Glass as a Partial Replacement for Fine Aggregate in Structural Concrete-Effects on Compressive Strength. Electronic Journal of Structural Engineering, 14(1): 116-122.

Ajagbe, W. O.; O .A. Ajele and M. A. Tijani. (2018). Partial replacement of sand with recycled plastic waste in structural concrete. Paper presented at the $17^{\text {th }}$ National conference of the Nigerians Institute of Environmental Engineers (NIEE), Held at Ralph Alabi Engineering Centre, Ikeja Branch of NSE Secretariat, Ogba, Lagos State, On 25th October, 2018, 28 - 31, Nigeria.

Ajamu S. O.; I. A. Raheem; S. B. Attah and J. O. Onicha. (2020). Effects of Partial Replacement of Fine Aggregate with Quarry Dust on Concrete Properties, LAUTECH Journal of Civil and Environmental Studies, 4(1): 16-23. https://doi.org/10.36108/laujoces/0202/40(0130).

Akinyele, J.O. and Ajede, A. (2018). The Use of Granulated Plastic Waste in Structural Concrete. African Journal of Science Technology and Innovation Development, 10(2): 169-75.

Almeshal, I.; B. A. Tayeh; R. Alyousef; H. Alabduljabbar and A. M. Mohamed. (2020). Eco-Friendly Concrete Containing Recycled Plastic as Partial Replacement for Sand. Journal of Material Research and Technology, 9(3): 4631-4643. https://doi.org/10.1016/j.jmrt.2020.02.090.

ASTM C136 (2006). Standard test method for sieve analysis of fine and coarse aggregates, ASTM American Society for Testing of Materials (ASTM), West Conshohocken, PA.

ASTM C127 (2012). Standard test method for density, relative density (Specic Gravity), and Absorption of Coarse Aggregate, American Society of Testing Materials (ASTM), West Conshohocken, PA.

ASTM D2487 (2011). Standard practice for classification of soils for engineering purposes, ASTM International, West Conshohocken, PA, USA.

BS 1881-125 (2013). Testing Concrete. Methods for mixing and sampling fresh concrete in the laboratory. London: British Standards Institution, London.

BS EN 12350-2 (2009). Testing fresh concrete. Slumptest. British Standards Institution, London.

BS EN 12390-3 (2019). Testing hardened concrete. Compressive strength of test specimens. British Standards Institution, London.

BS EN 12390-5 (2019). Testing hardened concrete. Flexural strength of test specimens. British Standards Institution, London.

BS EN 12390-6 (2019). Testing hardened concrete. Tensile splitting strength of test specimens. British Standards Institution, London.

BS EN 12390-7 (2019). Testing hardened concrete. Density of hardened concrete. British Standards Institution. London.

BS EN 197-1: (2011). Cement Composition, Specification and Conformity Criteria for Common Cements. British Standard Institution, (BSI), London.

BS EN 1992-1-1:2004+A1 (2014). Eurocode 2: Design of concrete structures- Part 1-1: General rules and rules for buildings. British Standards Institution, London.

Chhazed, A.; M. V. Makwana; N. Chavda and A. Navlakhe. (2019). Utilization of PET Waste in Plastic Bricks, Flexible Pavement and as Alternative Constructional Material - A review, International Journal of Applied Engineering Research, 14(3): 616-620.

Ellen MacArthur Foundation, (2017). The New Plastics Economy: Rethinking the Future of Plastics \& Catalysing Action, New Plastic Economy. https://doi.org/10.2443/skv-s-2013-51020130303.

Gopi, K. S.; T. Srinivas and S. P. Raju. (2020). Feasibility Study of Recycled Plastic Waste as Fine Aggregate in Concrete, $2^{\text {nd }}$ International Conference on Design and Manufacturing Aspects for Sustainable Energy (ICMED), 184: 1-5. https://doi.org/10.1051/e3sconf/202018401084.

Heidari, M.; P. P. Garnaik and A. Dutta. (2019). The Volarization of Plastic Via Thermal Means: Industrial Scale Combustion Methods, in: Al-Salem, S.M. (Ed.), Plastic to Energy, Plastic Design Library. William Andrew Publishing, pp. 295-312. DOI: 10.1016/B978-0-12-813140-4.00011-X.

Prakash, M. and Hemalatha, B. (2017). Replacement of waste material in concrete using recycled plastic. SSRG Int. J. Civ. Eng. (ICRTCETM-2017), 1: 9-14. 
Iowa (2020). Class Notes: C.C. Swan, University of Iowa: Lecture 2: Grain Size Distributions and Soil Particle Characteristics. Available online at: http://user.engineering.uiowa.edu/ swan/courses/53030/note s/gsd.pdf. Assessed 10 January, 2020.

Ismail, Z. Z., and AL-Hashmi, E. A. (2008). Use of Waste Plastic in Concrete Mixture as Aggregate Replacement. Waste Management, 28(11): 2041-2047. http://dx.doi.org/10.1016/j.wasman.2007.08.023.

Issa, C. A. and Salem, G. (2013). Utilization of Recycled Crumb Rubber as Fine Aggregates in Concrete Mix Design. Construction and Building Materials, 42: 48-52. http://dx.doi.org/1016/j.conbuildmat.2012.12.054.

Jaivignesh, B. and Sofi, A. (2017). Study on Mechanical Properties of Concrete using Plastic Waste as an Aggregate. IOP Conference Series: Earth and Environmental Science, 80(1): 12016.

Kaushal, N. and Vasistha, P. (2018). Replacement of Fine Aggregates with Waste PET in Concrete having Marble Dust as Additive Replacement of Fine Aggregates with Waste PET in Concrete having Marble Dust as Additive. Indian Journal of Science and Technology, 11(31) DOI: 10.17485/ijst/2018/v11i31/130592.

Lee, Z.H.; S. C. Paul; S. Y. Kong; S. Susilawati and X. Yang. (2019). Modification of Waste Aggregate PET for Improving the Concrete Properties. Advances in Civil Engineering, 1-10. https://doi.org/10.1155/2019/6942052.

Mastan, V. N. and Asadi, S.S. (2017). Pet Bottle Waste as a Supplement to Concrete Fine Aggregate. International Journal of Civil Engineering Technology, 8 (1): 558- 568.

Mohammed, A. A.; I. I. Mohammed and S. A. Mohammed. (2019). Some Properties of Concrete with Plastic Aggregate Derived Shredded from PVC Sheets. Construction and Building Materials, 201: 232-245. http://dx.doi.org/10.1016/j.conbuildmat.2018.12.145.

Mustafa, MA-T.; I. Hanafi; R. Mahmoud and B. A. Tayeh. (2019). Effect of Partial Replacement of Sand by Plastic Waste on Impact Resistance of Concrete: Experiment and Simulation. Structures, 20: 519-26.
Nadimalla, A.; S. A. B. Masjuki; A. B. Saad; K. B. Mohd Ismail and M. B. Ali. (2019). Polyethylene Terephthalate (PET) Bottles Waste as Fine Aggregate in Concrete, International Journal of Innovative Technology and Exploring Engineering (IJITEE), 8(6S4):1177-1180. DOI: 10.35940/ijitee.F1243.0486S419.

Neville, A.M. (2011). Properties of Concrete. Pearson Education, London.

Safi, B.; M. Saidi; D. Aboutaleb and M. Maallem. (2013). The use of plastic waste as fine aggregate in the selfcompacting mortars: Effect on physical and mechanical properties. Construction and Building Materials, 43: 436-442. http://dx.doi.org/10.1016/j. conbuildmat.2015.01.099.

Saikia, N. and de Brito, J. (2012). Use of Plastic Waste as Aggregate in Cement Mortar and Concrete Preparation: A Review. Construction and Building Materials, 34: 385-401. http://dx.doi.org/10.1016/j. conbuildmat.2012.02.066.

Saikia, N. and de Brito, J. (2014). Mechanical Properties and Abrasion Behaviour of Concrete Containing shredded PET Bottle Waste as a Partial Substitution of Natural Aggregate. Construction and Building Materials, 52: 236-244. conbuildmat.2013.11.049.

Samantaray, S. S.; K. C. Panda and M. Mishra. (2016). Rice Husk Ash as Fine Aggregate Sustainable Material for Strength Enhancement of Conventional and Self Compacting Concrete. Key Engineering Materials, 692: 94103 https://doi.org/10.4028/www.scientific.net/KEM.692.94.

Siddique, S.; T. Gupta; A. A. Thakare; V. Gupta and S. Chaudhary. (2019). Acid Resistance of Fine Bone China Ceramic Aggregate Concrete. European Journal of Environmental and Civil Engineering, 1-14. https://doi.org/10.1080/19648189.2019.1572543.

Umasabor, R.I. and Daniel, S.C. (2020). The effect of using polyethylene terephthalate as an additive on the flexural and compressive strength of concrete. Heliyon 6: 1-6. 